\title{
THE USE OF ADV IN WAVE FLUMES: GETTING MORE INFORMATION ABOUT WAVES
}

\author{
Claudio F. Neves ${ }^{1}$, Luiz Augusto M. Endres ${ }^{2}$, Conceição Juana Fortes ${ }^{3}$, \\ Daniel Spinola Clemente 4
}

\begin{abstract}
This article discusses the advantages of measuring wave orbital velocities in coastal two-dimensional physical models in addition to free surface profiles. A brief presentation of linear theory for partial standing wave is made and early experimental works on this subject are reviewed. Since 2005, additional experiments have been conducted on wave flumes in Brazil (INPH, IPH/UFRGS) and in Portugal (LNEC), in order to characterize wave patterns in terms of velocity data obtained by ADVs. A few questions are posed in the conclusion of the article, which aim at suggesting special care on the interpretation of velocity data, as used today, as well as proposing further research on the subject.
\end{abstract}

Keywords: velocity measurements; partial standing waves; clapotis; laboratory techniques

\section{INTRODUCTION}

There are several ways to describe a wave: surfers, engineers, scientists, sailors and sea watchers use the visual perception to estimate the free surface displacement. A diver or a fish, for whom there is no free surface, perceive the wave by oscillations in water velocity. This is exactly the point of view we obtain by using Doppler anemometers (laser or acoustic) to describe the fluid flow. For maritime hydraulics or coastal engineering, such kinematic description is very convenient to study sediment transport, induced forces on structures, identification of multiple wave groups, residual circulation in physical models and beaches. In all these examples, direct measurement or analysis of velocity records provides the key physical quantity to formulate or to solve an engineering problem.

Physical models in fluvial hydraulics have often required the measurement of free surface elevation, discharge and water velocity; instrumentation developed for steady or quasi-steady flow, though, was not adequate for use in maritime hydraulics and therefore, new instruments needed to be designed. Wave gauges were the first generation of these new electronic devices (e.g. Boudan 1953), but it took some time before the first instruments to measure unsteady and rapidly varying fluid velocities would be invented. Various technologies have been devised: hot wire and hot film, electromagnetic, laser Doppler anemometry, PIV, and acoustic Doppler anemometers. After the pioneering work of Kraus et al. (1994), the use of acoustic velocity meters have become a common practice in laboratory experiments. Since then, such instruments have undergone successive improvements (Lohrmann et al. 1994; Rusello et al. 2006; Schroevers et al. 2010), and the same physical principle has been used in field instruments, although current profilers have not yet been scaled down to laboratory size.

As a matter of fact, velocity measurements may provide additional information about the physical properties of the wave flow, such as particle acceleration and reflection coefficient, which may be relevant to coastal engineering studies, although such additional information very often is disregarded in small scale models. One possible explanation is that the free surface elevation is easily recorded, and most engineering traditional practice is based on wave height; another reason is the amount of turbulent fluctuation which is recorded on velocity measurements; a third reason might be lack of well established procedures for converting particle velocities into engineering design information.

Acoustic Velocity probes in laboratory require indeed careful positioning. Data should be carefully analyzed in order to account for slight deviations in vertical or horizontal orientation of the instrument. This article discusses possible analytical methods to improve the quality of data interpretation of ADV records and corrections which should be applied to the data. An example of a practical application to the study of partial reflection in wave flumes is shown.

\section{THEORETICAL BACKGROUND}

For progressive (linear) waves, vertical and horizontal components of the particle velocity are 90 degrees out of phase; in contrast, for pure standing waves (clapotis), both vertical and horizontal components are in phase. A graph which plots the time history of the velocity vector (referred to as

\footnotetext{
${ }^{1}$ Professor, COPPE, Federal University of Rio de Janeiro, Cx.Postal 68508, Rio de Janeiro, RJ, 21949-900, Brazil, neves@peno.coppe.ufri.br

2 Professor, IPH, Federal University of Rio Grande do Sul, Porto Alegre, RS, 21949-900, Brazil, endres@ufrgs.br

${ }^{3}$ Principal Investigator, National Laboratory of Civil Engineering (LNEC), Av. do Brasil 101, Lisbon, Portugal, jortes@Inec.pt

${ }^{4}$ Graduate Research Assistant, Federal University of Itajubá, Itajubá, MG, Brazil, daniel spinola@hotmail.com
} 
hodograph in this article) easily show these two different situations: an ellipsis for the progressive wave and a segment of straight line for the clapotis. Any discrepancy in phase between the two velocity components or in the shape of the hodograph would be an indicator of partial reflection. Wallet \& Ruelan (1950) experimental studies depict particle trajectories under progressive and (partial) standing waves (also shown in Wiegel 1965).

For near breaking waves, nonlinear effects significantly distort the wave velocity pattern, such that the hodograph depart significantly from the usual elliptical pattern predicted by linear theory. In 3D laboratory studies, even monochromatic waves present a rather complex pattern of particle velocity which results from wave-wave interactions, the influence of secondary currents, the presence of undesired multiple reflections or seiching in the basin. Hence, experimental measurements should account for these effects and data interpretation should be based on stronger theoretical background, rather than simply using transfer functions given by linear theory.

\section{Orbital velocity}

Consider the velocity potentials for an incident wave $\left(\varphi_{\mathrm{i}}\right)$ and a reflected wave $\left(\varphi_{\mathrm{r}}\right)$ propagating in opposite direction, the total velocity will be obtained as the linear superposition of both waves.

$$
\left\{\begin{array}{l}
\varphi_{i}(x, y, z, t)=-\frac{H_{i}}{2} \frac{g}{\sigma} \frac{\cosh [k(z+h)]}{\cosh k h} \sin (k x-\sigma t) \\
\varphi_{r}(x, y, z, t)=\frac{H_{r}}{2} \frac{g}{\sigma} \frac{\cosh [k(z+h)]}{\cosh k h} \sin (k x+\sigma t+\varepsilon)
\end{array}\right.
$$

where the indexes $i$ and $r$ refer to incident and reflected wave, respectively, $\varphi$ is the velocity potential, $H$ is the wave height, $h$ is the water depth, $k$ is the wave number, $\sigma$ is the angular frequency, $g$ is gravity, and $(x, y, z)$ is the spatial position.

The resulting velocity field $(u, v, w)$ is given by the following expressions:

$$
\begin{aligned}
& \left(\begin{array}{l}
u \\
v \\
w
\end{array}\right)=-\nabla\left(\varphi_{\mathrm{i}}+\varphi_{\mathrm{r}}\right)= \\
& =\frac{g k}{\sigma}\left(\begin{array}{c}
\frac{\cosh [k(z+h)]}{\cosh k h}\left\{\frac{H_{i}+H_{r}}{2} \sin \left(k x+\frac{\varepsilon}{2}\right) \sin \left(\sigma t+\frac{\varepsilon}{2}\right)+\frac{H_{i}-H_{r}}{2} \cos \left(k x+\frac{\varepsilon}{2}\right) \cos \left(\sigma t+\frac{\varepsilon}{2}\right)\right\} \\
0 \\
\frac{\sinh [k(z+h)]}{\cosh k h}\left\{-\frac{H_{i}+H_{r}}{2} \cos \left(k x+\frac{\varepsilon}{2}\right) \sin \left(\sigma t+\frac{\varepsilon}{2}\right)+\frac{H_{i}-H_{r}}{2} \sin \left(k x+\frac{\varepsilon}{2}\right) \cos \left(\sigma t+\frac{\varepsilon}{2}\right)\right\}
\end{array}\right)
\end{aligned}
$$

Neglecting the transverse y-direction, the field velocity can be expressed as

$$
\begin{aligned}
& \left(\begin{array}{l}
u \\
w
\end{array}\right)= \\
& =\frac{g k}{2 \sigma \cosh k h}\left(\begin{array}{ll}
\left(H_{i}-H_{r}\right) \cos (k \hat{x}) \cosh [k \hat{z}] & \left(H_{i}+H_{r}\right) \sin (k \hat{x}) \cosh [k \hat{z}] \\
\left(H_{i}-H_{r}\right) \sin (k \hat{x}) \sinh [k \hat{z}] & -\left(H_{i}+H_{r}\right) \cos (k \hat{x}) \sinh [k \hat{z}]
\end{array}\right)\left(\begin{array}{c}
\cos (\sigma \hat{t}) \\
\sin (\sigma \hat{t})
\end{array}\right)
\end{aligned}
$$

where $[k \hat{z}]=[k(z+h)],(k \hat{x})=(k x+\varepsilon / 2)$ and $(\sigma \hat{t})=(\sigma t+\varepsilon / 2)$.

It should be noted that the determinant of the matrix which involves the incident and reflected wave height is only a function of the incident wave height, the reflection coefficient and the vertical elevation.

$$
\operatorname{det}\left(\begin{array}{ll}
A & B \\
C & D
\end{array}\right)=\left(H_{i}^{2}-H_{r}^{2}\right) \cosh [k \hat{z}] \sinh [k \hat{z}]=H_{i}^{2}\left(1-R^{2}\right) \cosh [k \hat{z}] \sinh [k \hat{z}]
$$

Therefore, if the first order terms of the vertical and horizontal velocity components were measured at the same height from the bottom, at different positions along a wave flume, the quantity expressed by equation (4) should remain invariant. 
On the other hand, if the velocities were plotted (hodograph) at different locations along the flume or at different heights above the bottom, the appearance of the plots would be ellipses, with major axis tilted at different angles along the flume, as shown in Figure 1. This result agrees with the experimental observations of particle trajectories photographed by Walet and Ruelan (1953).

Looking at the dimensions of the major $(M)$ and minor axes $(m)$ of the ellipses of the velocity hodograph, another surprising result was found which significantly differentiate progressive waves from partial clapotis.

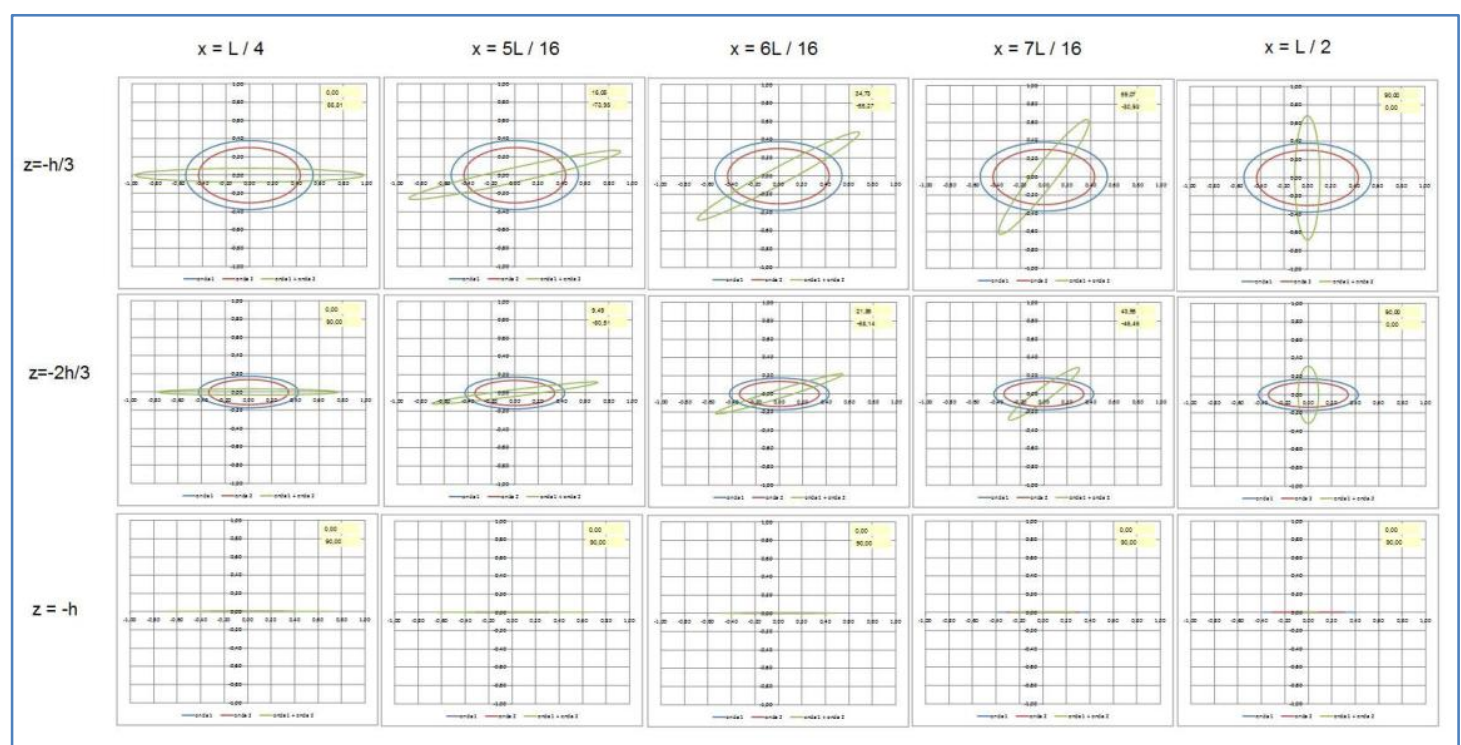

Figure 1. Hodograph of wave total velocity (incident + reflected) along direction of propagation and vertical direction.

The axes of the ellipses may be expressed in terms of the incident and reflected wave heights (or in terms of the incident wave height $H_{i}$ and the reflection coefficient $R$ ), the position along the flume and the height above the bottom as:

$$
\begin{aligned}
& M=g k H_{i} \\
& =\frac{1}{2 \sigma \cosh k h}\left\{\frac { 1 } { 2 } \left[\left(1+R^{2}\right) \cosh [2 k \hat{z}]-2 R \cos (2 k \hat{x})\right.\right. \\
& \left.\left.+\sqrt{\left(1+R^{2}\right)^{2}+2 R^{2} \cosh [4 k \hat{z}]+2 R^{2} \cos (4 k \hat{x})-4 R\left(1+R^{2}\right) \cosh [2 k \hat{z}] \cos (2 k \hat{x})}\right]\right\}^{\frac{1}{2}} \\
& m=g k H_{i} \\
& =\frac{1}{2 \sigma \cosh k h}\left\{\frac { 1 } { 2 } \left[\left(1+R^{2}\right) \cosh [2 k \hat{z}]-2 R \cos (2 k \hat{x})\right.\right. \\
& \left.\left.-\sqrt{\left(1+R^{2}\right)^{2}+2 R^{2} \cosh [4 k \hat{z}]+2 R^{2} \cos (4 k \hat{x})-4 R\left(1+R^{2}\right) \cosh [2 k \hat{z}] \cos (2 k \hat{x})}\right]\right\}^{1 / 2}
\end{aligned}
$$

In the case of a pure progressive wave $(R=0)$, the usual expressions from linear theory are retrieved, and the size of $M$ and $m$ are no longer a function of the position along the wave propagation. This is not the case for a partial clapotis. However, when looking at the ellipsis focal distance, defined as

the following expression is obtained:

$$
f=\sqrt{M^{2}-m^{2}}
$$

$$
\begin{gathered}
f^{2}=\left(\frac{g k}{2 \sigma \cosh k h}\right)^{2} H_{i}^{2}\left\{\left(1+R^{2}\right)^{2}+2(R)^{2} \cosh [4 k \hat{z}]+2(R)^{2} \cos (4 k \hat{x})\right. \\
\left.-4 R\left(1+R^{2}\right) \cosh [2 k \hat{z}] \cos (2 k \hat{x})\right\}^{1 / 2}
\end{gathered}
$$


For a pure progressive wave, $R=0$, the focal distance remains constant throughout the fluid domain. Therefore, if the velocity history is measured at different locations, computing the focal distance of the hodographs may be an efficient way to identify (or even to quantify) the reflection coefficient.

At last, one may also compute the angle at which the (major axis of) ellipsis is tilted. As a starting point, consider the correlation between horizontal and vertical components of the velocity, defined by the expression

$$
\langle u(t), w(t)\rangle=\frac{1}{T} \int_{t_{1}}^{t_{1}+T} u(t) \cdot w(t) d t
$$

Next, the correlation matrix is built as

where

$$
\mathbf{F}=\left(\begin{array}{cc}
\langle u(t), u(t)\rangle & \langle u(t), w(t)\rangle \\
\langle u(t), w(t)\rangle & \langle w(t), w(t)\rangle
\end{array}\right)=\left(\begin{array}{cc}
\frac{1}{2}\left(A^{2}+B^{2}\right) & \frac{1}{2}(A C+B D) \\
\frac{1}{2}(A C+B D) & \frac{1}{2}\left(C^{2}+D^{2}\right)
\end{array}\right)
$$

$$
\left(\begin{array}{ll}
A & B \\
C & D
\end{array}\right)=\frac{g k}{2 \sigma \cosh k h}\left(\begin{array}{cc}
\left(H_{i}-H_{r}\right) \cos (k \hat{x}) \cosh [k \hat{z}] & \left(H_{i}+H_{r}\right) \sin (k \hat{x}) \cosh [k \hat{z}] \\
\left(H_{i}-H_{r}\right) \sin (k \hat{x}) \sinh [k \hat{z}] & -\left(H_{i}+H_{r}\right) \cos (k \hat{x}) \sinh [k \hat{z}]
\end{array}\right)
$$

The eigenvalues of matrix $\mathbf{F}$ are computed as the roots of the equation

$$
\begin{gathered}
\operatorname{det}\left(\begin{array}{cc}
\frac{1}{2}\left(A^{2}+B^{2}\right)-\lambda & \frac{1}{2}(A C+B D) \\
\frac{1}{2}(A C+B D) & \frac{1}{2}\left(C^{2}+D^{2}\right)-\lambda
\end{array}\right)=\lambda^{2}-\frac{1}{2}\left(A^{2}+B^{2}+C^{2}+D^{2}\right) \lambda+\frac{1}{4}\left[(A D-B C)^{2}\right]=0 \\
\Rightarrow\left\{\begin{array}{l}
\lambda_{+}=\frac{1}{2}\left[\frac{1}{2}\left(A^{2}+B^{2}+C^{2}+D^{2}\right)+\frac{1}{2} \sqrt{\left(A^{2}+B^{2}+C^{2}+D^{2}\right)^{2}-4(A D-B C)^{2}}\right]=\frac{1}{2} M^{2} \\
\lambda_{-}=\frac{1}{2}\left[\frac{1}{2}\left(A^{2}+B^{2}+C^{2}+D^{2}\right)-\frac{1}{2} \sqrt{\left(A^{2}+B^{2}+C^{2}+D^{2}\right)^{2}-4(A D-B C)^{2}}\right]=\frac{1}{2} m^{2}
\end{array}\right.
\end{gathered}
$$

which are related to both axis of the ellipsis. The eigenvectors associated to these eigenvalues are determined by the expressions:

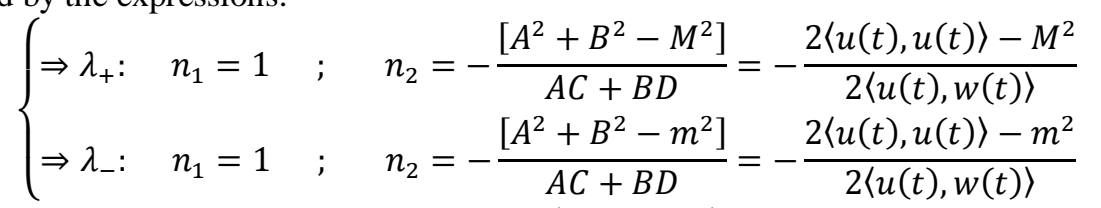

In case of a pure progressive wave, such that $\langle u(t), w(t)\rangle=0$, the eigenvectors are $(1,0)$ and $(0,1)$, the horizontal and vertical directions, respectively.

\section{EXPERIMENTAL SET-UP}

Experiments have been conducted in wave flumes at the National Laboratory of Civil Engineering (LNEC), in Portugal (Endres and Capitão 2010; Neves et al. 2012), at the National Institute of Waterways Research (INPH) (Lima et al. 2006), and at the Hydraulic Research Institute of the Federal University of Rio Grande do Sul (IPH/UFRGS), both in Brazil. In all these examples, monochromatic waves were used.

The experiments at LNEC aimed at studying highly nonlinear or near breaking waves at various locations along the flume (Figures 2 and 3). Particle velocities were measured by Vectrino II instruments in order to estimate wave heights and these estimates were compared to direct measurements of free surface elevation. The experiments at INPH aimed at studying wave attenuation by a field of flexible nylon ropes, intended to simulate aquatic plants; two Sontek $10 \mathrm{MHz}$ instruments were used, one downlooking and the other side looking devices, positioned at different vertical elevation at the center line of the flume, just downdrift from the "vegetation" field (Figure 4). The experiments at IPH/UFRGS used the same instruments as those at INPH; they aimed at obtaining wave kinematic properties in order to estimate free surface elevations (progressive waves) as well as to describe the velocity field associated to partial standing wave. It was of particular interest verifying how long it took for the regular wave train to be disrupted by multiple reflections at a 1:10 beach or a vertical brick wall (Figure 5). 
At all these experiments, it became clear that instrument positioning should be conducted very carefully. Different from field ADV, the laboratory versions of ADVs used in these experiments did not have any positioning devices which could guarantee either their vertical or the longitudinal alignment. Even a slight tilting or rotation (yaw) of the ADV sensors provides a false reading in one of the velocity components. For instance, if the instrument is off vertical, the horizontal component of the wave particle velocity is projected onto the "vertical" direction (as assumed by the instrument), giving a false reading. The same reasoning holds if the instrument is not aligned with the longitudinal direction of the wave flume, and the horizontal component of the particle velocity gives a false reading of a transverse velocity. It turns out that readings on the flume transverse direction is very often just disregarded; yet, they might contain part of the wave momentum and energy signal, due to a slight misalignment.

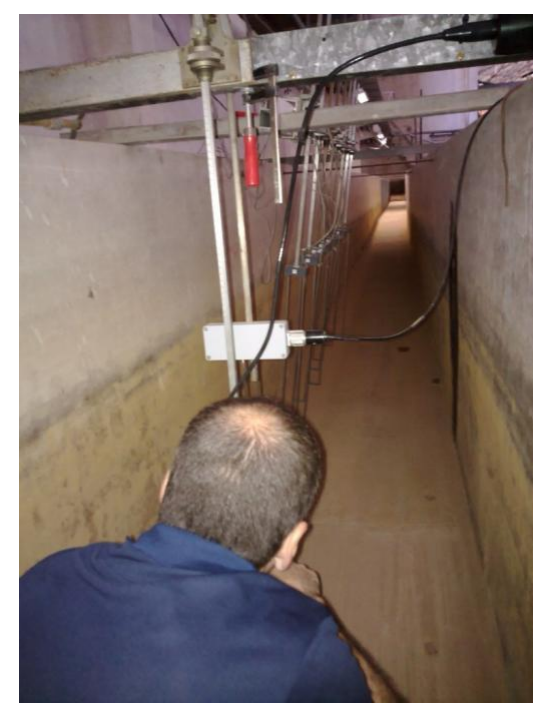

(A)

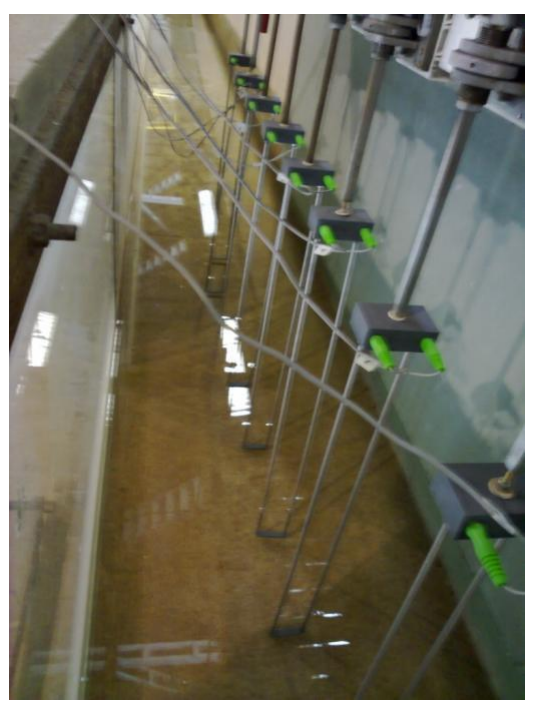

(B)

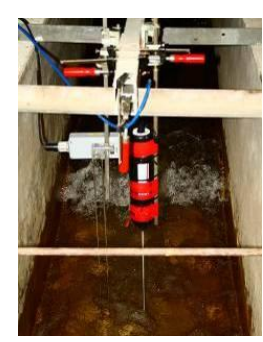

(C)

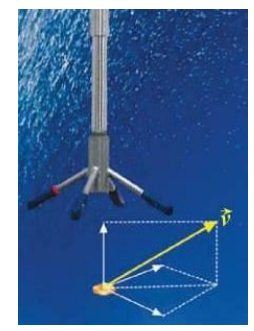

(D)

Figure 2. Wave flume at LNEC (Portugal), showing deployment of instruments and acoustic velocimeter. (Neves et al. 2012). (A) Visual positioning of the probes; (B) array of wave gauges; (C) ADV set-up; (D) schematic view of sensor.

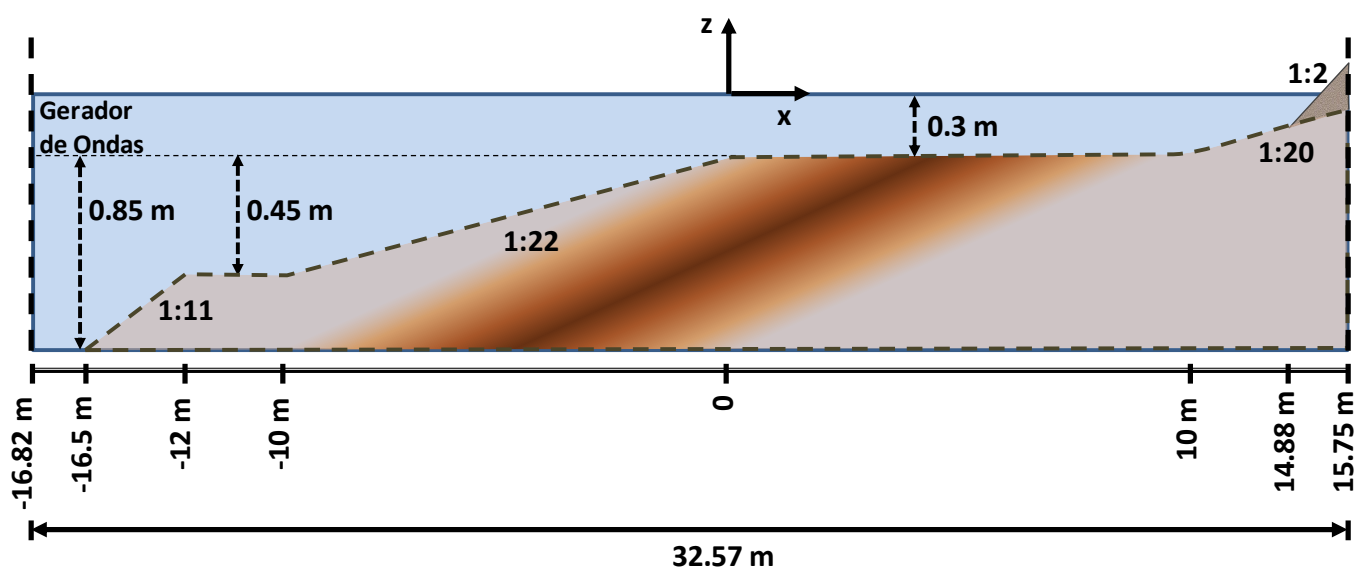

I
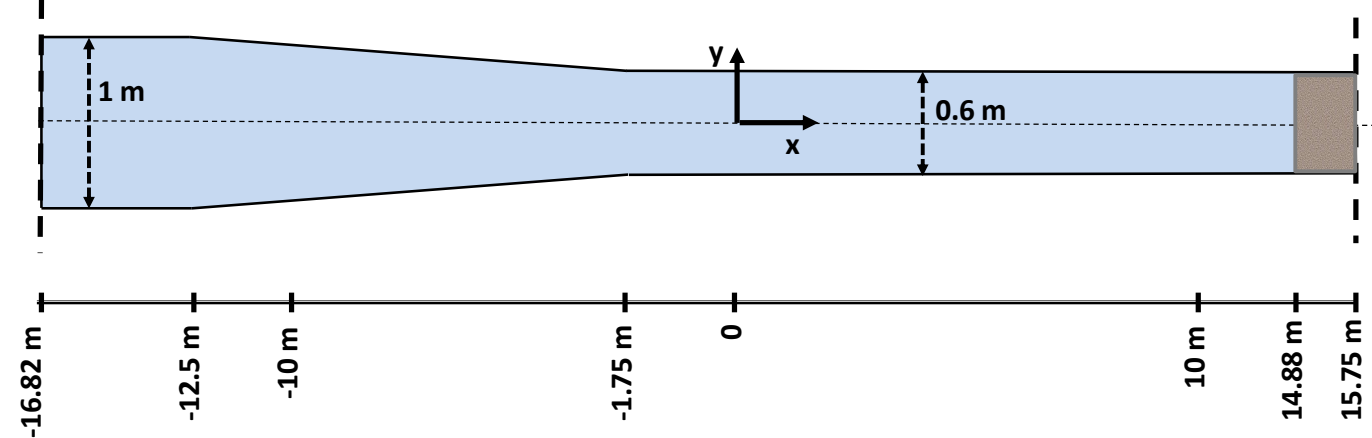

Figure 3. Schematic view of wave flume at LNEC (Portugal). 


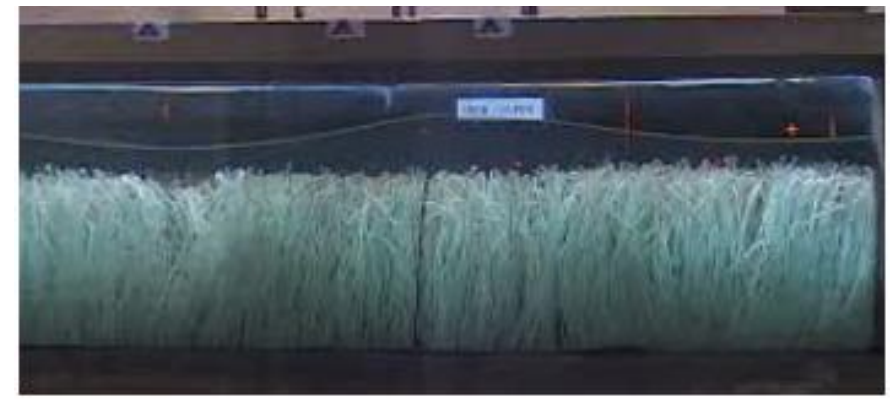

(A)

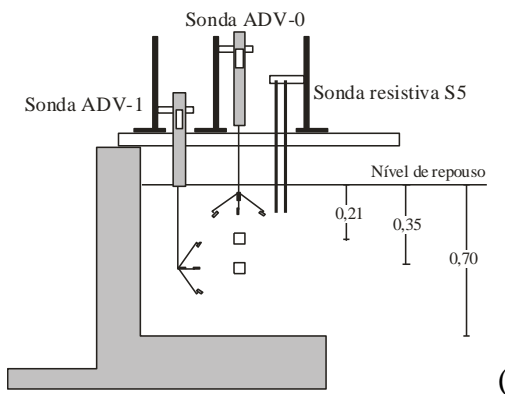

(B)
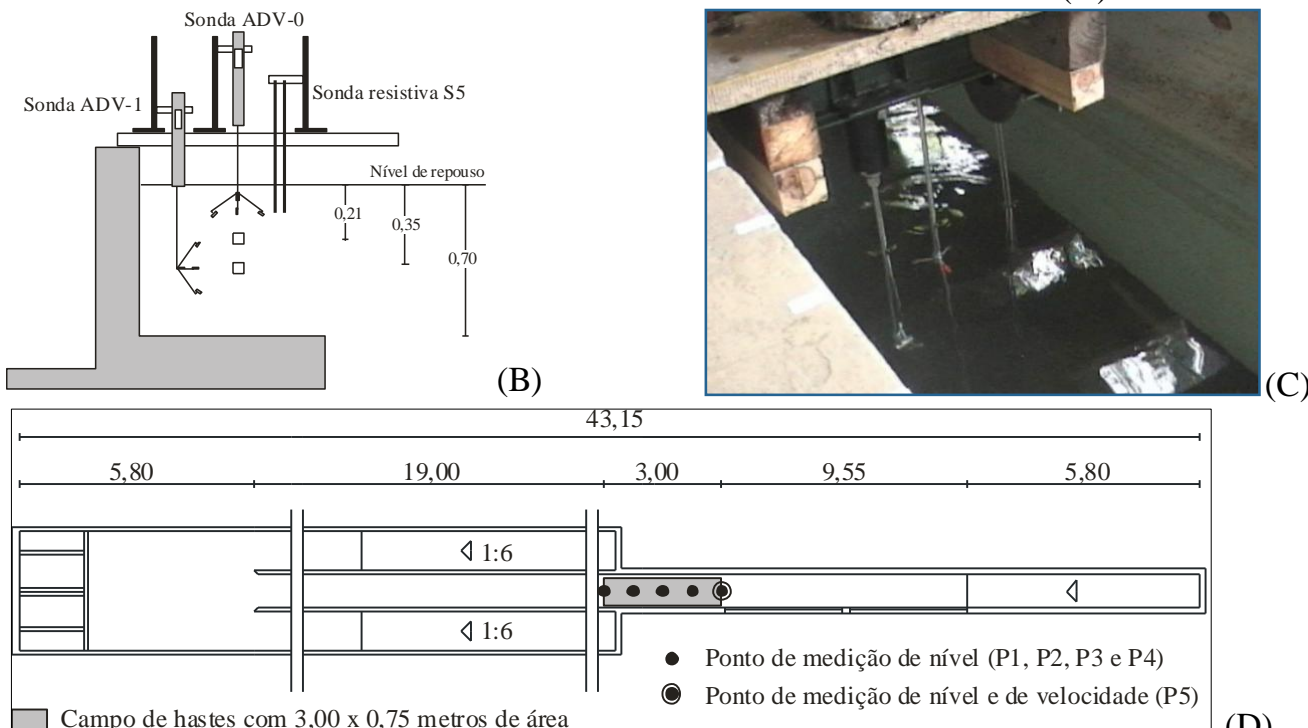

Figure 4. Schematic view of experimental set-up in the wave flume at INPH (Brazil) for studies of wave attenuation by flexible elements (Lima et al. 2006). (A) Side view of experimental set-up; (B) schematic positioning of ADVs; (C) view of instruments; (D) wave flume dimensions in meters.
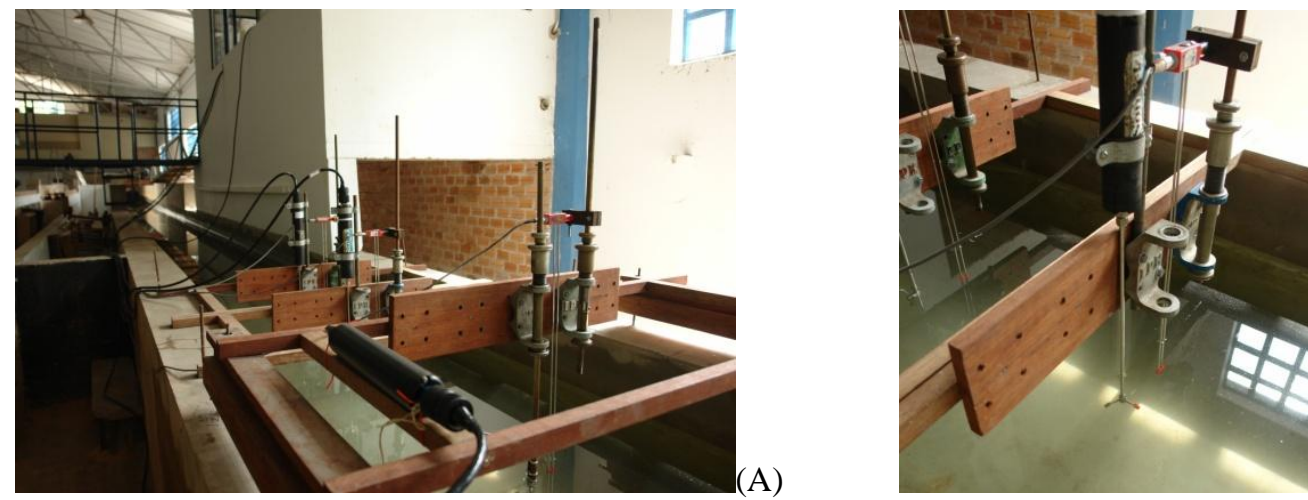

(B)

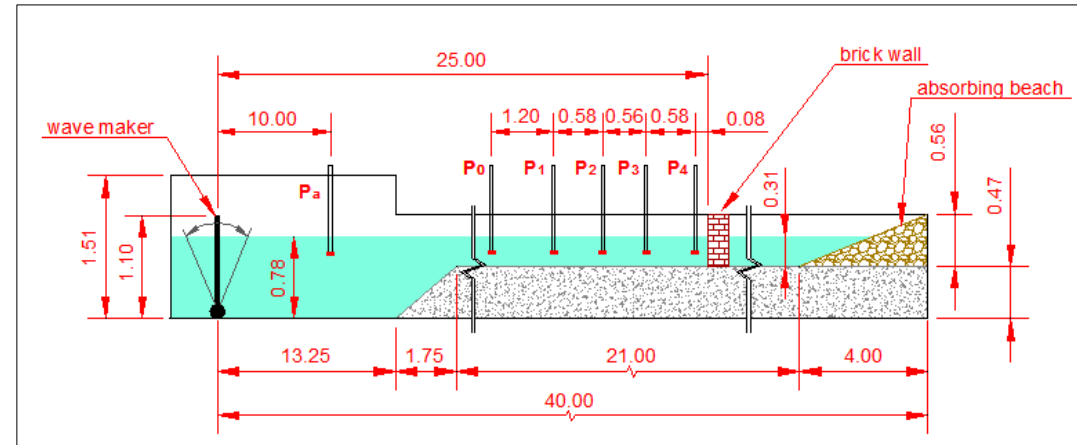

(C)

Figure 5. Experimental set-up at IPH/UFRGS (Brazil) for studying partial standing waves. (A) Wave flume and instrument positioning; (B) detailed view of ADV and wave gauge; (C) schematic view of wave flume. 
Positioning instruments is not an easy task in fluid mechanics experiments or monitoring procedures. Three examples of measurement devices will be discussed next, neither of them directly related to wave oscillatory flows.

When the axis of the head of a Pitot tube under use is not aligned with the mean flow direction but forms an angle $\theta$ with it, the differential pressure recorded, $\Delta \mathrm{p}_{\theta}$, is different from the true differential pressure $\Delta \mathrm{p} 0$. In (ISO 3966) the sensitivity to inclination of three currently used Pitot tubes, which are the AMCA, NPL and CETIAT types, is showed in Figure 6. Accordingly to this figure, for these types of Pitot tubes and with inclination angles less than 5 degrees the difference $\left(\Delta p_{\theta}-\Delta p_{0}\right) / \Delta p_{0}$ does not exceed $0.5 \%$ in absolute values (ISO, 1977).

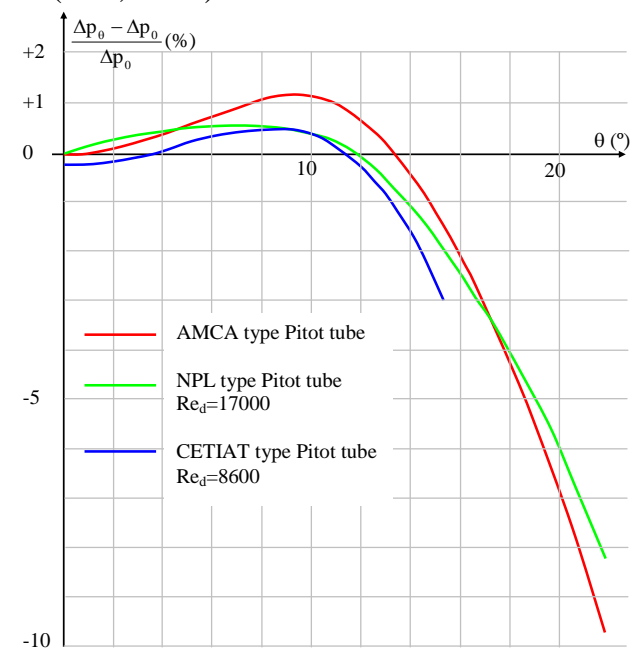

Figure 6. Values of the relationship between $\theta$ and pressure difference for some Pitot tube types (adapted from ISO 3966, where $\operatorname{Re}_{d}=(U . d / v), U=$ flow velocity; $d=$ Pitot tube diameter; $v$ = kinematics viscosity of the fluid).

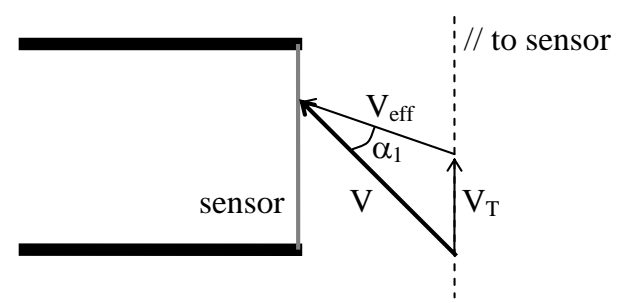

Figure 7. Schematic view of a hot wire anemometer: velocity components at sensor (adapted from Goldstein, 1983).

For an infinitely long wire, the angle sensitivity of the hot wire is expressed as (figure ??2)

$$
V_{e f f}=V \cos \theta_{1}
$$

where $V$ is the flow velocity and $V_{\text {eff }}$ is the effective cooling velocity past the sensor. This equation essentially states that the velocity along the sensor $\left(V_{T}=V \sin \theta_{1}\right)$ has no cooling effect on the sensor and that the sensor is rotationally symmetrical in both construction and response. In many calculations and experiments the equation is adequate, maintains simplicity and, depending on probe and sensor design, can be quite accurate. Nevertheless, because the sensor has a finite length, there is heat transfer due to the flow parallel to the sensor $\left(V_{T}\right)$. To account for this, a second term is added to equation 13

$$
V_{e f f}=V \sqrt{\cos ^{2} \theta_{1}+k_{T}^{2} \sin ^{2} \theta_{1}}
$$

where $k_{T}$ is an empirically determined factor. Although $k_{T}$ is not truly a constant for all velocities and values of $\theta_{1}$, for a limited velocity range and angles from $0^{\circ}$ to $60^{\circ}$ a fixed value works quite well. The equation given here provides concrete example but does not imply that it always represents the best functional relationship. It should be emphasized that, in using a single calibrated sensor in turbulence 
intensities under $20 \%$, good accuracy can be obtained even without equation (14). Considerations about probe alignment become important when multi-sensor probes are used in large turbulence intensities, or when the sensor orientations during calibration and use are different.

Sonic anemometers have been largely used in meteorology, long before the development of ADVs. According to current practice, these instruments must be leveled with inclinometers to a precision of 0.1 degree, in order to provide reliable information regarding horizontal momentum fluxes (e.g. Deacon, 1968). Very seldom the topography of the terrain is described with such a precision, mainly in micro-meteorological studies. The key decision is whether the instrument should be maintained at horizontal level or should follow local slope and flow streamlines; this is particularly relevant on steep slopes. It has been well reported in the literature the effects of tilted anemometers on cross contamination of velocities, therefore influencing the computation of turbulent stresses and momentum fluxes. Wilczak et al. (2001) have developed and compared three algorithms for correcting data obtained by tilted anemometers, namely Double Rotation, Triple Rotation and Planar Fit, and concluded that the last one provides better results. These methods might as well be used as a procedure for quantifying the magnitude and direction of tilt. In this remarkable paper, Wilczak and co-authors address a very useful subject for those who deal with acoustic devices in beach environments or wave flume/basins.

\section{Procedure for testing the angle of tilting}

A slight inclination of the probe (vertical positioning) or poor alignment with the flume (horizontal positioning) result in velocity components in three directions $\left(u^{\prime}, v^{\prime}, w^{\prime}\right)$, while in the idealized desired condition within the flume there should exist only two components of the wave orbital velocity, in the vertical and longitudinal directions. The cross-flume velocity component is often discarded as turbulence, but a doubt remains: should it really be? Could this cross-flume velocity be as an indicator that something in the experiment is not going so well? What should be the influence of beach slope on the measurement of the wave velocity field? Answers to these questions will be addressed later.

Besides careful manual/visual positioning, special interpretation methods have been devised at all experiments mentioned in this article. For instance, locking the probe at a fixed position relative to the walls of the flume or with respect to the vertical direction is the first attempt. In the experimental set-up at IPH/UFRGS, it was not possible though to guarantee the vertical positioning, due to the fixation rig available as well as because the walls of the flume were not leveled at the point where the probes were installed. For this reason, additional care was necessary in order to assure the best possible positioning. In any case, installing the ADVs turned out to be a lengthy procedure (Figure 8).

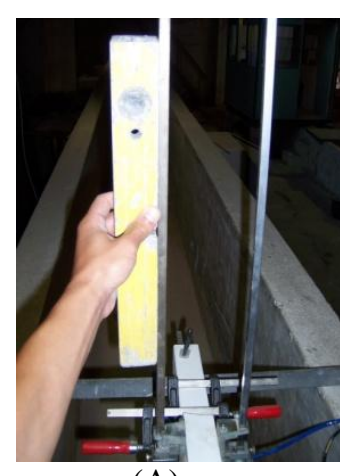

(A)

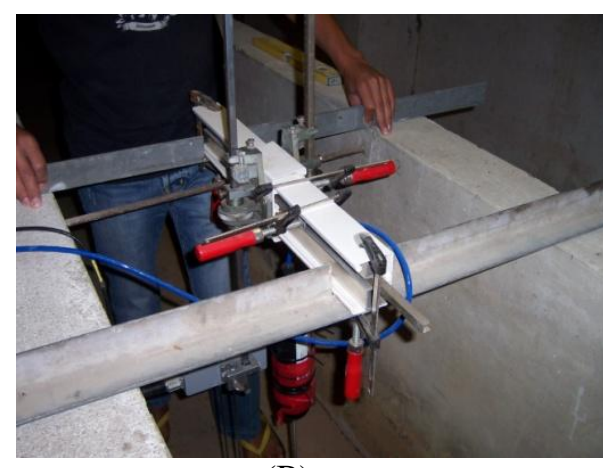

(B)

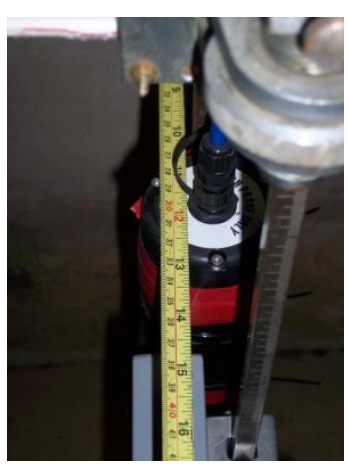

(C)

Figure 8. Positioning the ADV in the wave flume. (A) leveling; (B) and (C) positioning at the center of flume.

Another way to verify the positioning was devised using the results provided by the instrument, plotting two components at a time, superposing the three graphs $\left(w^{\prime} \times u^{\prime}\right),\left(u^{\prime} \times v^{\prime}\right)$, and $\left(v^{\prime} \times w^{\prime}\right)$. A typical result is shown in Figure 9. In case of misalignment, some sort of loop should appear. The red dots represent the vertical ( $\left.w^{\prime}\right)$ and the longitudinal ( $\left.u^{\prime}\right)$ components; there seems to be a slight tilting of the graph. The green dots represent the vertical $\left(w^{\prime}\right)$ and the transversal (v') components, while the white dots represent the longitudinal $\left(u^{\prime}\right)$ and the transversal ( $\left.v^{\prime}\right)$ components; both graphs do not show a loop, there is a general linear trend, indicating that one component seems not be dependent on the other. As a matter of fact a significant spread of velocity readings was observed, which was attributed to turbulence, since the wave was considerably nonlinear. However, a very small misalignment might generate such behavior. 


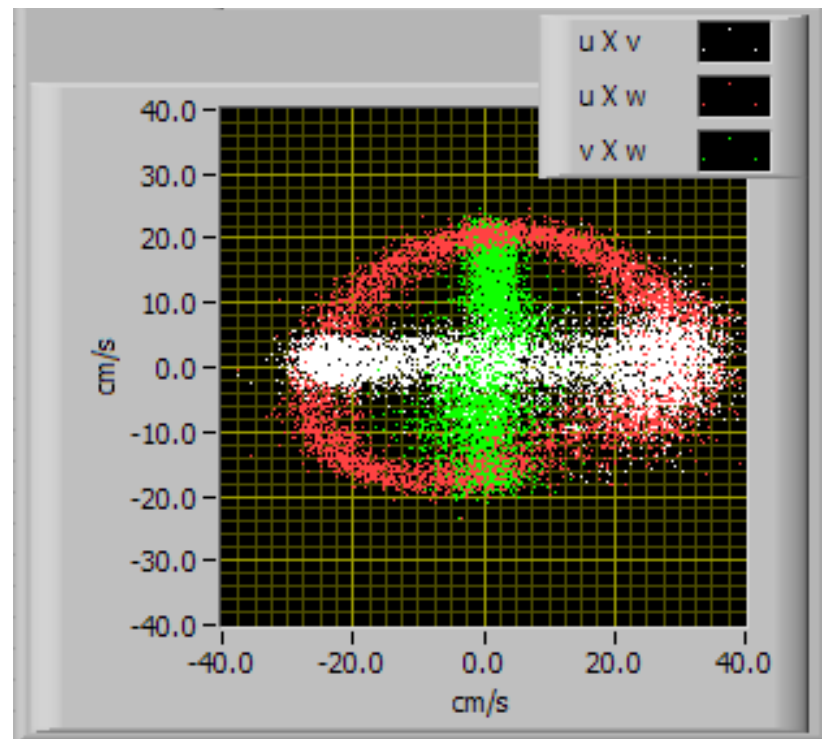

Figure 9. Plot of 3 velocity components $(u, v, w)$ in pairs. Observe a slight tilting of the red graph $(u \times w)$

The mathematical method devised by Lima et al. (2006) consists on determining the principal directions (eigenvectors) of the stress tensor built upon the actual measured velocity components, regardless of the probe positioning.

Taking the definition given by equation 9 , the stress tensor $\mathbf{F}$ is computed using the three components of the velocity,

$$
\mathbf{F}=\left(\begin{array}{ccc}
\langle u(t), u(t)\rangle & \langle u(t), v(t)\rangle & \langle u(t), w(t)\rangle \\
\langle v(t), u(t)\rangle & \langle v(t), v(t)\rangle & \langle v(t), w(t)\rangle \\
\langle w(t), u(t)\rangle & \langle w(t), v(t)\rangle & \langle w(t), w(t)\rangle
\end{array}\right)
$$

The eigenvectors are then determined and the velocity readings are projected in these directions. This method is similar to the Triple Rotation presented by Wilczak et al. (2001).

Because the tensor $\mathbf{F}$ is symmetrical, the eigenvectors are orthogonal to each other. For a progressive wave, the main direction (largest eigenvalue) should coincide with the direction of the propagation of the wave and the second main direction would be the vertical direction. Ideally, in a wave flume, the terms involving the cross-flume velocities should be zero and the corresponding eigenvector would be the cross-flume direction. For a partial standing wave, though, the main direction is aligned with angle of the major axis of the ellipsis of the hodograph (Figure 1), and the second direction would be along the minor axis.

However, if the eigenvectors of stress tensor $\mathbf{F}$, thus computed with the wave data obtained from an ADV, are not aligned in the longitudinal and vertical directions of the flume, two conditions may exist:

1. the instrument is not properly aligned with the flume;

2. a partial standing wave may be present.

The above dilemma can be solved simply by sliding the probe along the flume, as long as it remains at the same height above the bottom and at the same position relative to the walls.

Further, if the stress tensor $\mathbf{F}$ shows significant contributions in the cross-flume direction or the values are not dominant in one given component, two interpretations may hold:

1. the instrument is not properly aligned with the flume;

2. a parasite transverse (standing) wave may be present.

The above considerations are of most relevance when using an ADV in a wave basin. Different from a wave flume, in this case, it is not evident what is the major direction of propagation and how to relate it to the main eigenvectors; in addition, wave reflection in a wave basin is not co-aligned with the incident wave. Finally, taking the experience from sonic anemometers in meteorology, the bottom slope may play an important role on velocity measurements and stress computation. This remains an important issue for further research. 


\section{RESULTS}

The experiments at LNEC illustrated how much nonlinear effects manifest themselves on wave orbital velocities, as the wave shoals. A total of 15 conditions were tested, except wave height of $18 \mathrm{~cm}$ and period $1.1 \mathrm{~s}$, which were too steep, at three positions along the flume (1:20 slope):

- wave period: $1.1,1.5,2.0$, and 2.5 seconds

- control wave height: $12,14,16$, and $18 \mathrm{~cm}$

- position along flume: 200,500 , and $800 \mathrm{~cm}$

- depth at corresponding position: 20,35 , and $50 \mathrm{~cm}$

- distance above bottom: 7,13,20 cm

These experiments also indicated that a linear transfer function from velocity to wave height should be used with extreme caution, mainly for nonlinear waves. This statement seems quite obvious, however some instruments do perform such a conversion, either with pressure or with velocity signals.

Figure 10 shows the hodograph for vertical and horizontal velocities, measured at position $800 \mathrm{~cm}$, for a wave with $18 \mathrm{~cm}$ height at control station and $2.5 \mathrm{~s}$ period. In this figure it is evident how far the hodograph velocities depart from the (linear) elliptical pattern. A filter was used in order to maintain signal below $1.64 \mathrm{~Hz}$ (period above $0.61 \mathrm{~s}$ ) and to eliminate signal or noise above $2.50 \mathrm{~Hz}$ (period below $0.493 \mathrm{~s}$ ); this filter keeps up to the fourth harmonic of the studied wave. The filter frequency response function is given on the inset of Figure 10.

A complete different picture of the flow is obtained when individual velocity components are analyzed separately, as shown in Figure 11. The same filter shown in Figure 10 was used. One can identify on the cross-flume component $(\mathrm{Vy})$ that a coherent signal exists with the same basic frequency of the main wave, a very likely indication that the signal is being contaminated by the vertical (or even the horizontal) component. This picture stresses the advantages of analyzing the orbital velocity as a vector quantity, rather than three independent scalar quantities.

Figure 12 shows how much the velocity components change along the flume, as the wave shoals from $(\mathrm{A})$ (water depth $=50 \mathrm{~cm}$ ) to $(\mathrm{C})$ (water depth $=20 \mathrm{~cm}$ ). As waves approach breaking, the flow is rather irregular, in spite of presenting a typical nonlinear still organized profile. It seems therefore that observations of particle velocities allow identifying more complex phenomena, in contrast to surface profile measurement. This phenomenon was later investigated at the IPH/UFRGS wave flume.

The studies at IPH/UFRGS aimed at investigating wave reflection from a 1:10 beach made of stone and from a brick wall; results will be shown from this latter case. The wave maker did not account for correction due to wave reflection; therefore this investigation had an additional purpose to identify how long a test could run before the wave became meaningless. Compared to usual wave profile measurements, velocity data turned out to be much more accurate on identifying the breakdown of the organized motion or the appearance of spurious motion, such as transverse standing wave.

For all testing conditions water depth was maintained at $31.1 \mathrm{~cm}$ and two wave periods were tested, 1.18 and $1.82 \mathrm{~s}$; each experimental condition was run three times. Four ADVs were positioned at 23.2, 23.78, 24.34, and $24.92 \mathrm{~m}$ from the wave maker, named P1, P2, P3, and P4, respectively; the brick wall was built $25 \mathrm{~m}$ from the wave maker. A control wave gauge was placed $10 \mathrm{~m}$ from the wave maker (location PA), another one at a distance of $22 \mathrm{~m}$ (named P0), and next to each ADV a wave gauge was also installed (see Figure 5). Because only two ADVs were available, the tests were first conducted at points $\mathrm{P} 1$ and $\mathrm{P} 2$, then the instruments were moved to locations P3 and P4; the wave gauges PA and P0 were used as control for both sets of experiments. P1 and P3 were side-looking ADV, positioned $21 \mathrm{~cm}$ above the bottom; P2 and P4 were downlooking instruments, positioned 18.1 and $17.8 \mathrm{~cm}$ above the bottom, due to a gentle slope of the bottom.

Table 1 shows the time history of the three velocity components, measured at points P1 through P4, as well as their spectrum, computed using LNEC's software (SAM). It is interesting to observe that, at a given time, there is a significant increase in longitudinal velocity; this event corresponds to the moment that the wave, which is reflected both at the wall and at the wave maker, reaches the monitoring position. 


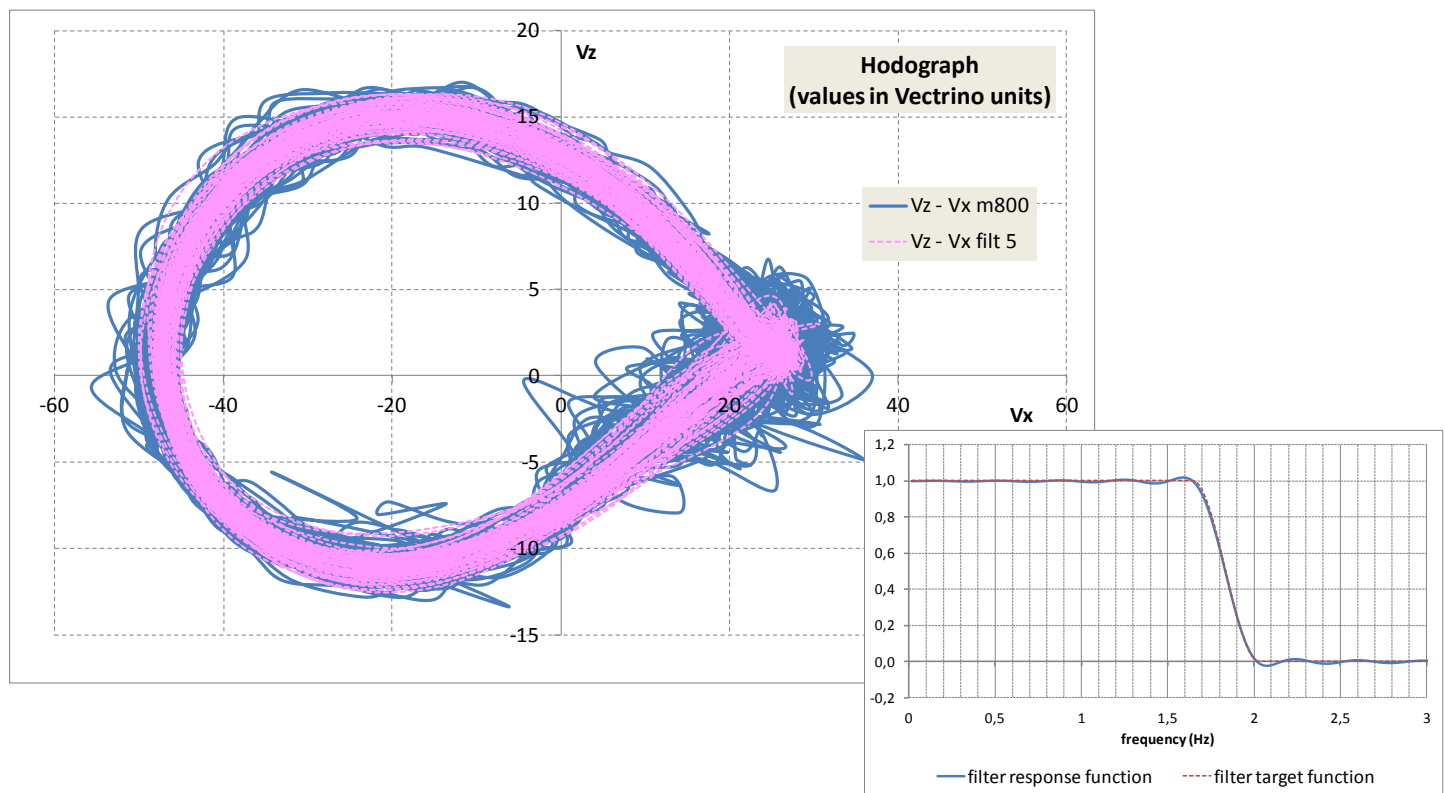

Figure 10. Plot of velocity components: vertical (Vz) and horizontal along the flume (Vx). Negative values indicate motion towards the beach. Wave period: $2.5 \mathrm{~s}$; height: $18 \mathrm{~cm}$; position: $800 \mathrm{~cm}$. Blue line= raw data; Purple line $=$ filtered data.

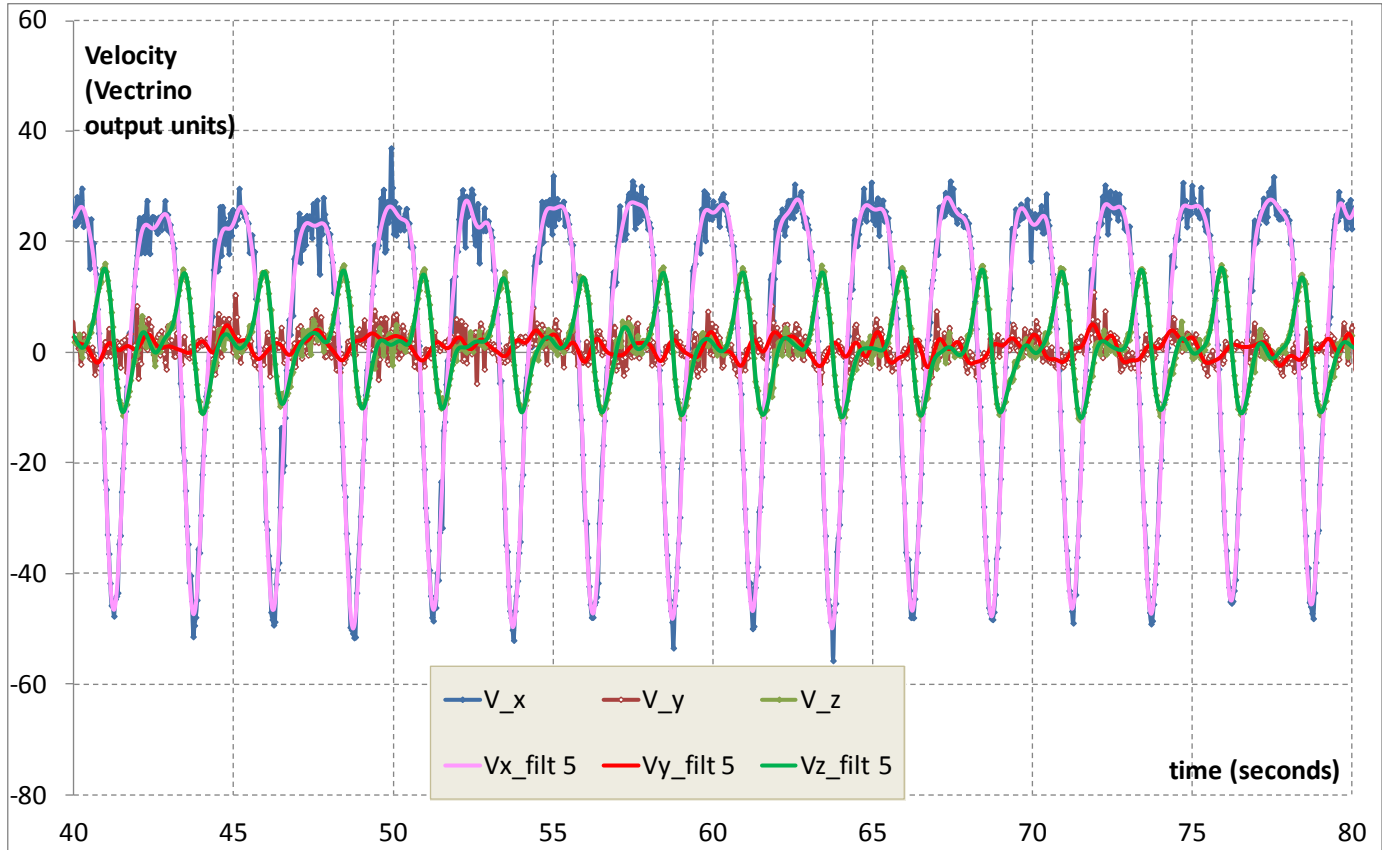

Figure 11. Plot of velocity components: vertical (Vz), horizontal along the flume (Vx), horizontal across the flume $(\mathrm{Vy})$. Wave period: $2.5 \mathrm{~s}$; height: $18 \mathrm{~cm}$; position: $800 \mathrm{~cm}$. Blue line= raw data.

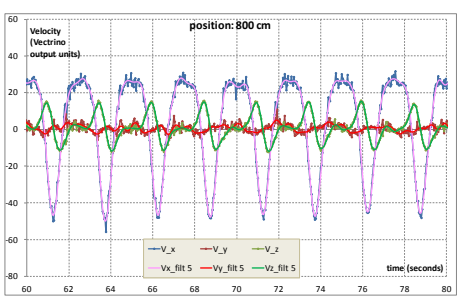

(A)

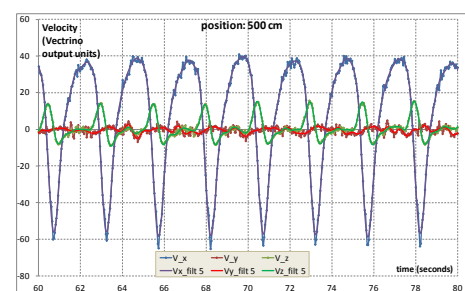

(B)

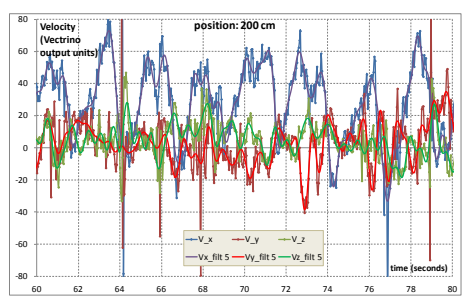

(C)

Figure 12. Velocity components at three locations along the flume: (A) $800 \mathrm{~cm}$, (B) $500 \mathrm{~cm}$ and (C) $200 \mathrm{~cm}$. 


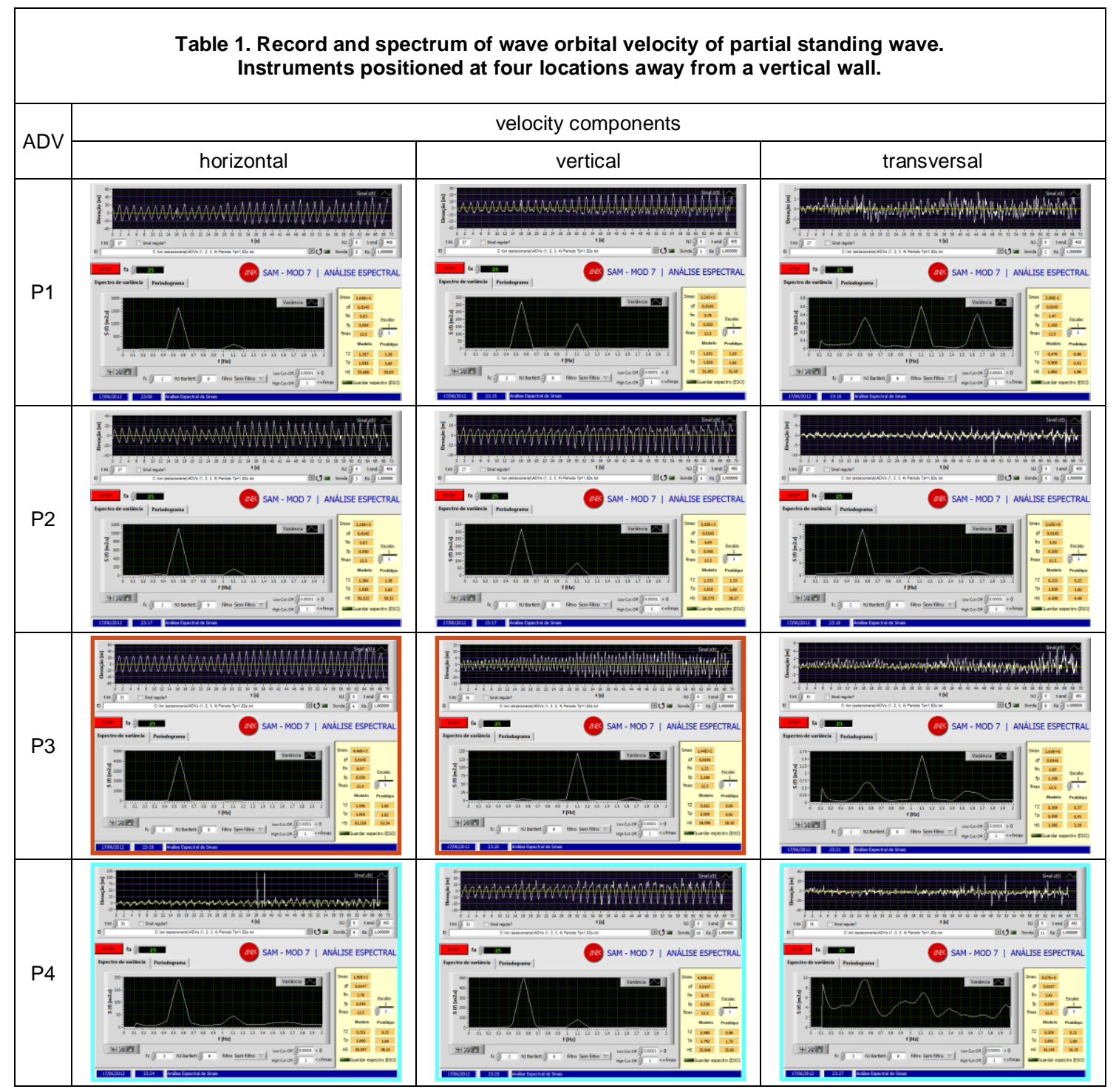

Regarding the spectral representation, the case P3 deserves special attention, as shown in Figure 13. The vertical velocity (upper picture) is of the order of 4 times smaller than the horizontal velocity (lower picture). This is an indication of a quasi-node for a partial standing wave. However, the spectral peak of the vertical velocity happens at twice the fundamental frequency of the wave. This is both in theoretical and experimental agreement with early studies conducted at Laboratoire Dauphinois d'Hydraulique (NEYRPIC 1952; NEYRPIC 1954; Chabert d'Hyères 1960). The transverse velocity, although being about half the magnitude of the vertical velocity, shows the spectral peak at twice the fundamental frequency, but there is a secondary peak at the fundamental frequency. This can be interpreted as a cross-contamination of the velocity signal, due mainly to poor alignment of the probe. Yet, past some time, the signal evolves to an almost chaotic pattern, indicating that standing transverse waves have set in.

Case $\mathrm{P} 4$, the point closest to the wall, is particularly interesting because both longitudinal and transversal velocity components have comparable magnitudes, yet their spectra are completely different. While the former presents a peak at the fundamental frequency, the latter is indeed a broad band spectrum. This result was confirmed in the other experiments, and provides an alert that a very special flow pattern may develop near the wall; therefore, one may conclude that no component should be a priori disregarded, before careful exam of possible interference due to misalignment of the probe, as well as the onset of a more complex flow. 

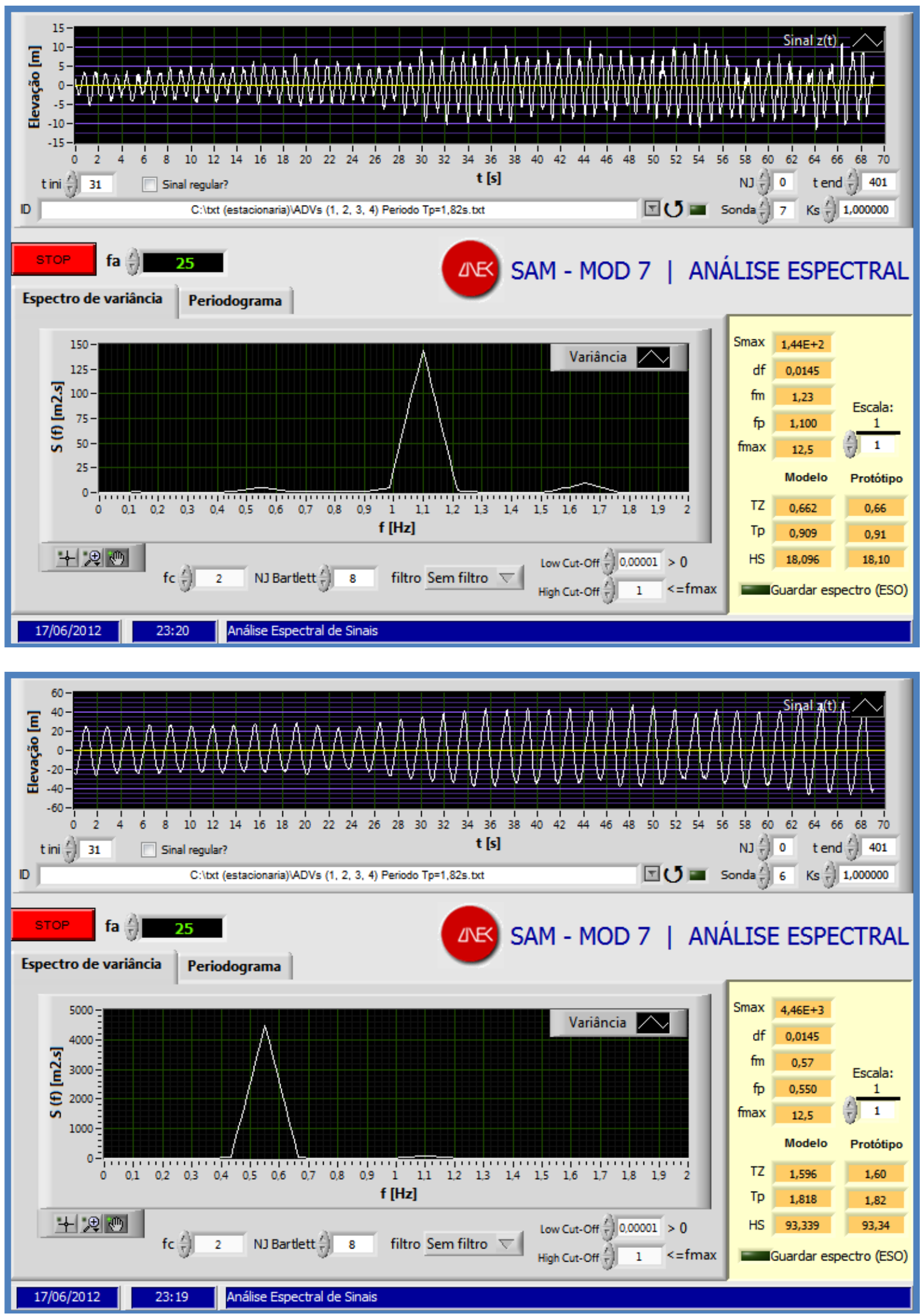

Figure 13. Velocity components at point P3: vertical velocity (upper picture), horizontal longitudinal velocity (lower picture). 


\section{CONCLUSION}

Tests conducted in wave flumes proved that velocity measurements made with Acoustic Doppler Velocimeters (ADV) are more sensitive to high and low frequency perturbations than elevation measured by point gauges. Although this should not be quite surprising, it was easier by far to identify the formation of spurious standing waves and increasing turbulence before the free surface signaled the perturbation. This is of particular concern when analyzing wave forces on structures, breakwater stability, and sandy beach evolution in coastal physical models. Therefore, one should never disregard the cross-flume velocity component as it may contain significant information.

One disadvantage of using ADV data is the scatter on orbital velocities. This handicap can be significantly reduced by means of adequate filtering techniques. As a matter of fact, it is possible to design digital filters which produce a smooth signal which keeps the desired wave harmonics.

It seems that hodographs can provide better visualization than time history of independent velocity components. Further, with the use of hodographs, it is possible to identify tilted probes and the presence of wave reflection. However, if the hodograph is skewed (approximately an ellipsis, if only first order harmonics is kept), one may not a priori diagnose whether the instrument is tilted or (partial) reflection is present.

Indeed, wave reflection in flumes is very difficult to control or it is just not controlled at all. As a result, non-stationary waves, either longitudinal or transversal to the flume, may appear. Therefore, the use of adaptative techniques, such as HHT, would be more appropriate, rather than Fourier spectral methods. At least, one could identify when the experimental wave pattern had changed to a point of no longer representing the desired model conditions.

Theoretically, wave reflection coefficients may be obtained from geometrical properties of hodographs along flume. Special geometrical expressions were obtained from linear theory which turned out to be invariant along the flume or showed specific behavior along the vertical at a given section. It is very likely that those expressions presented in this article can be adjusted to quantify reflection coefficient, a subject being currently researched by the authors.

At last, a list of intriguing puzzles is posed as guidance for the on-going research:

- the presence of bottom slope: it seems that the experience from meteorological measurements with sonic devices might be transferred to coastal waves monitoring;

- $\quad$ wave kinetic energy: this might be a quite reasonable control variable in physical models;

- $\quad$ effect of walls or other structures on the phase of the reflected wave;

- description of the velocity field near walls or blocking structures;

- time evolution of wave pattern during long runs.

\section{ACKNOWLEDGMENTS}

The authors acknowledge funding for this research by CAPES Foundation of the Brazilian Ministry of Education (Grant PROCAD 053/2007) and the Foundation for Science and Technology of the Ministry of Science, Technology and Higher Education of Portugal - FCT (Grant CAPES-FCT 242/2009). The authors thank LNEC, INPH and IPH/UFRGS for letting them use the experimental facilities as well as having the collaboration of their personnel who worked in those experiments. A special thank is addressed to Prof. Geraldo Maciel (UNESP - State University of São Paulo "Julio de Mesquita Filho" at Ilha Solteira) for lending the acoustic velocimeters, within the CAPES Project "Friends of Boussinesq".

\section{REFERENCES}

Boudan, M. (1953). Instruments for the measurement of rapidly varying levels on hydraulic models. $L a$ Houille Blanche, Août-Sept., p. 526-545.

Bullock, G.N. and Short, I. (1985). Water particle velocities in regular waves. Journal of Waterway, Port, Coastal and Ocean Engineering, ASCE, Vol. 111, 2: 189-200.

Chabert d'Hyères, G. (1960). Étude du clapotis. La Houille Blanche, no. 2, p. 153-163.

Craig, R.G.A; Loadman, C.; Clement, B.; Rusello, P.J.; Siegel, E. (2010). Characterization and Testing of a new Bistatic Profiling Acoustic Doppler Velocimeter: The Vectrino-II. Proceedings of the IEEE/OES/CWTM Tenth Working Conference on Current Measurement Technology, IEEE, p. 246-252.

Deacon, E. L. (1968). The leveling error in Reynolds Stress measurement. Bull. Amer. Meteorol.Soc. 49, 836.

Ehrnström, M. and Villari, G. (2009). Discrete and Continuous Dynamical Systems Series B, Vol. 12, no. 3, p. 539-559, doi:10.3934/dcdsb.2009.12.539. 
Endres, L.A.M.; Capitão, R. (2010). A comparison of time and spectral analyses on physical simulations of wave records in flumes. Coastlab 2010, Barcelona - $3^{\text {rd }}$ International Conference dealing with the Application of Physical Modelling to Port and Coastal Protection.

Goldstein, R. J. (1983). Fluid mechanics measurements. New York : Springer Verlag.

Hughes, S.A. (1992). Estimating wave-induced bottom velocities at vertical wall. Journal of Waterway, Port, Coastal, and Ocean Engineering, ASCE, vol. 118, 2: 175-192.

ISO - International Organization for Standardization (1977). ISO 3966 Measurement of fluid flow in closed conduits - Velocity area method using Pitot static tubes. Geneve: ISO, 1977.

Kraus, N.C.; Lohrmann, A; Cabrera, R. (1994). New acoustic meter for measuring 3D laboratory flows. Journal of Hydraulic Engineering, ASCE, vol. 120, 3: 406-412.

Lima, S.F.; Neves, C.F.; Rosauro, N.M.L. (2006). Damping of gravity waves by fields of flexible vegetation. Proceedings of $30^{\text {th }}$ International Conference on Coastal Engineering, ASCE.

Lohrmann, A; Cabrera, R.; Kraus, N.C. (1994). Acoustic-Doppler Velocimeter (ADV) for laboratory use. Fundamentals and Advancements in Hydraulic Measurements and Experimentation. Proceedings. ASCE. August 1-5, 1994, Buffalo, New York, USA.

Luhar, M.; Coutu, S.; Infantes, E; Fox, S.; and Nepf, H. (2010). Wave-induced velocities inside a model seagrass bed. Journal of Geophysical Research, 115, C12005, doi:10.1029/2010JC006345.

Neves, D.R.C.B.; Endres, L.A.M.; Fortes, C.J.E.M.; Okamoto, T. (2012). Directional spreading model in a wave channel: wave propagation and wave breaking. Ocean Engineering, 55: 148-160.

NEYRPIC - Laboratoire Dauphinois d'Hydraulique (1954). Trajectories in a total clapotis Comparison between experimental results and theoretical trajectories. La Houille Blanche. p.76-78. (in French)

NEYRPIC - Laboratoire Dauphinois d'Hydraulique (1952). Description installation d'études sur la physique de expérimentales la houle. La Houille Blanche. p.843-847. (in French) http://dx.doi.org/10.1051/lhb/1952055

Rusello, P.J.; Lohrmann, A.; Siegel, E.; Maddux, T. (2006). Improvements in acoustic Doppler velocimetry. Proceedings of $7^{\text {th }}$ International Conference on Hydroscience and Engineering ICHE-2006. 10-13 Sep., Philadelphia, USA. p.1-16.

Schroevers, M.; Huisman, B.J.A.; van der Wal, M.; Terwindt, J. (2010). Measuring ship induced waves and currents on a tidal flat in the Western Scheldt Estuary. Proceedings of the IEEE/OES/CWTM Tenth Working Conference on Current Measurement Technology, IEEE, p. 123-129.

Snyder, W.H., and Castro, I.P. (1999). Acoustic Doppler velocimeter evaluation in stratified towing tank. Journal of Hydraulic Engineering, ASCE, vol.125, 6: 595-603.

Umeyama, M. (2011). Coupled PIV and PTV measurements of particle velocities and trajectories for surface waves following a steady current. Journal of Waterway, Port, Coastal, and Ocean Engineering, ASCE, Vol. 137, 2: 85-94. DOI: 10.1061/(ASCE)WW.1943-5460.0000067.

Walet, A., and Ruelan, F. (1950). Trajectories of particles within partial standing waves. La Houille Blanche, Juillet-Août, p.483 and photographic supplement.

Wiegel, R.L. 1965. Oceanographical Engineering, Prentice-Hall, Englewood Cliffs, New Jersey, 531 pp.

Wilczak, J.M.; Oncley, S.P.; Stage, S.A. (2001). Sonic anemometer tilt correction algorithms. Boundary Layer Meteorology. 99: 127-150. 